\title{
Genetic diagnosis of embryos: Clear explanation, not rhetoric, is needed
}

\author{
Chantal Bouffard PhD, Stéphane Viville PhD, Bartha Maria Knoppers JD
}

Previously published at www.cmaj.ca

$\mathrm{E}$ mbryonic research and genetic testing continue to raise concerns. ${ }^{1}$ With controversy comes debate and, sometimes, distortion of facts through the use of loaded terms and concepts that call to mind both historical events and science fiction.

Achieving greater public understanding of genetic diagnosis of embryos, known generally as preimplantation genetic diagnosis (see definitions of terms in Appendix 1, available at www.cmaj.ca/cgi/content/full/cmaj.080658/DC1), has implications for the development of regulations and health policies for a broad field that includes genomics, reproductive genetics and embryonic research. ${ }^{2}$ We examine the debate about genetic testing and embryonic research with particular reference to the use of words and concepts that have distorted public and scientific discourse in ways that could have a negative influence on laws and regulations for new reproductive technologies generally.

\section{Genetic diagnosis of embryos}

Genetic diagnostic testing of embryos is the first reproductive genetic service combining genetic testing and in vitro fertilization that is widely available and offered in a clinical setting. Like prenatal diagnosis, it can allow for the selection of embryos that are free of single-gene defects (e.g., cystic fibrosis and Huntington chorea) and frequently occurring chromosomal abnormalities including aneuploidy (e.g., Down syndrome) before the embryos are implanted in the uterus. (See other examples of genetic abnormalities in Appendix 2, available at www.cmaj.ca/cgi/content/full/cmaj.080658 /DC1). It can also be used specifically to screen for aneuploidy and to determine the sex of an embryo. Unlike prenatal diagnosis, preimplantation genetic diagnosis is not performed when a woman is pregnant. Rather, it is performed on embryonic cells that have been conceived in vitro.

Two diagnostic approaches can be used. One is known as polymerase chain reaction and the other as chromosome visualization by fluorescence in situ hybridization (FISH). $\infty$ Polymerase chain reaction allows for the amplification of target DNA sequences to facilitate the diagnosis of single-gene defects and the identification of sex in X-linked diseases. Chromosome visualization by fluorescence in situ hybridization is used to screen for aneuploidy, to identify chromosomal abnormalities and to determine sex in X-linked diseases (Figure 1).

\section{Key points}

- Genetic diagnostic testing of embryos raises legal and socioethical issues.

- The use by experts of terms such as "eugenics" and "the perfect child" needlessly polarizes debate.

- It is the potential for social uses of these novel techniques that pose a eugenic threat.

- Clear explanations rather than rhetoric will promote adoption of sound public policy in this controversial field.

Quite apart from questions of the availability of these techniques is the issue of their rates of success. From the very first step of a procedure to the birth of a child, the process of genetic diagnostic testing of embryos is not without the risk of failure (Figure 2). Nevertheless, from 2004 to 2006, more than 1000 children were born following the use of these techniques. ${ }^{3}$ As well as providing greater reproductive choice for parents, genetic diagnosis of embryos is integral to progress in predictive and regenerative medicine and to a number of therapeutic developments centred on the human embryo. Furthermore, as reproductive genetic services in general become increasingly diverse (Appendix 3, available at www.cmaj.ca /cgi/content/full/cmaj.080658/DC1), worldwide demand for them is growing.

\section{Why language matters}

Important ethical considerations are at stake when experts use expressions such as "eugenics" or "the perfect child." This choice of language confuses fiction with reality. It also risks miring the debate on preimplantation genetic diagnosis in rhetorical quicksand. Moreover, it obstructs the clear presentation of the values and arguments embraced and defended by those who have genuine and important reservations about this technique. Finally, because people are naturally inclined to

From the Division of Genetics (Bouffard), Department of Pediatrics, Faculty of Medicine and Health Sciences, Université de Sherbrooke, Sherbrooke, QC; the Department of Cell and Developmental Biology (Viville), Institute of Genetics and Molecular and Cellular Biology, Faculté de Médecine, Université Louis Pasteur, Illkirch, France; and the Centre of Genomics and Policy (Knoppers), Faculty of Medicine, Department of Human Genetics, McGill University, Montréal, QC

Cite as CMAJ 2009.DOI:10.1503/cmaj.080658 
view the discourse of academics as scientific discourse, such language can undermine critical analysis.

It is important that we try to learn whether the choice of language and concepts used in the debate is representative of the current values in a given society or whether it instead serves the interests of specific groups. For example, in our research in France, we observed a significant gap between the values embraced by couples who sought recourse to preim-

\section{A) FISH (fluorescence in situ hybridization)}

a) Probes: 11 centromere chromosome 11 long arm chromosome 22 long arm

b) Parental Chromosomes

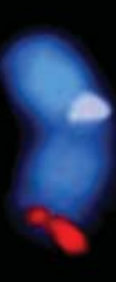

11

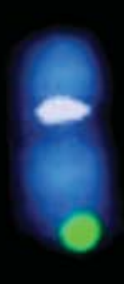

der(11)

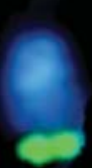

22

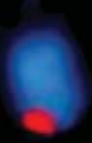

der(22) c) FISH on Blastomere Nuclei

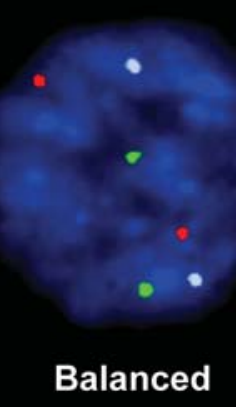

Unbalanced

trisomy 11q + Monosomy 22q

\section{B) PCR (polymerase chain reaction)}

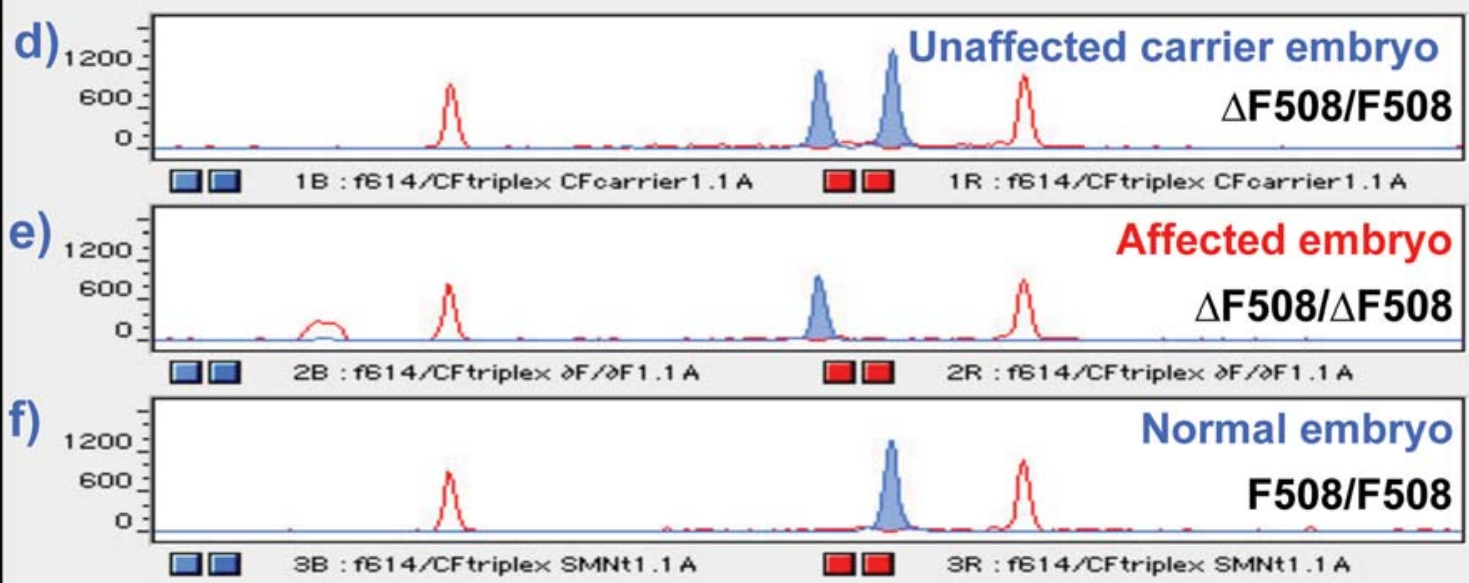

Figure 1: Preimplantation genetic diagnosis using (A) fluorescence in situ hybridization (FISH) for a reciprocal translocation and (B) for $\Delta$ F508 mutation in cystic fibrosis after polymerase chain reaction (PCR). (a) Three probes were used: centromere probe of chromosome 11 was labelled in blue, the subtelomeric probe for the long arm of chromosome 11 was labelled in red, and the subtelomeric probe for the long arm of chromosome 22 was labelled in green. (b) Normal and derivative parental chromosomes are visualized by FISH using the 2 probes on chromosomes of the parent with the translocation. Two hybridization signals for each of the 2 probes can be observed. (c) Results of FISH for a balanced (left) and an unbalanced (right) embryo. Only balanced embryos, with normal chromosomes or with the balanced translocation, can be transferred into the uterus for a pregnancy. Two hybridization signals for each of the 2 probes can be observed in balanced or normal embryos. In unbalanced embryos, there are 2 blue spots, corresponding to the centromere of chromosome 11, and either 3 red signals (partial trisomy 11q) and 1 green signal (partial monosomy 22q), or 1 red signal (partial monosomy 11q) and 3 green signals (partial trisomy 11q). (d) Electropherograms of a preimplantation genetic diagnosis for $\Delta$ F508 mutation in cystic fibrosis after migration of PCR products on ABI3100 automatic analyzer. PCR products are shown in blue and internal size standard in red. Both parents are heterozygous for the $\Delta \mathrm{F} 508$ mutation. Results of preimplantation genetic diagnosis show (d) an unaffected carrier embryo ( $\Delta$ F508/F508), (e) an affected embryo ( $\Delta F 508 / \Delta F 508$ ) and (f) a normal embryo (F508/F508). 
plantation genetic diagnosis and certain values enshrined in French laws that govern bioethics. ${ }^{4}$

If this distortion of reality through recourse to sensationalizing language and concepts is deployed as part of national and international decision-making processes for the development of health policies and the governance of preimplantation genetic diagnosis, it could trigger a slippery slope as perilous as the social, medical and technological ones that participants in the debate wish to avoid. In the Canadian context, this concern is especially important and timely because the Assisted Human Reproduction Act, which received royal assent in 2004, is slated to undergo Parliamentary review in 2009. Preimplantation genetic diagnosis is one of the practices that will be regulated under this legislation. Assisted Human Reproduction Canada, the federal regulatory agency that oversees matters relating to assisted human reproduction, was established under the Assisted Human Reproduction Act.

The reality is that such distortions lend credibility to the "slippery slope" and "beginning of the end" arguments. The result could be the hasty adoption of specific laws or health policies based on unwarranted fears. Such measures create a further layer of distortion, in contrast to what would be the case with regulatory measures based on a realistic response to facts and experience. The notions of "eugenics" and "the perfect child", in particular, are exercising undue influence on policy choices and thus limiting access to genetic diagnosis. ${ }^{5}$ In France, Bioethics Law no. 94-654, which governs the donation and use of elements and products of the human body, medically assisted procreation or prenatal diagnosis, prohibits testing for more than 1 genetic condition on an embryo conceived as part of a preimplantation genetic diagnostic procedure. The prohibition applies even when there is a known risk that more than 1 condition is present. The fear of eugenics and the premise that parents will want children tailored to their whims underlies such legislative measures.

\section{Eugenics}

Because genetic diagnosis of embryos involves geneticallybased selection of embryos, its eugenic potential cannot be denied. It is not the technique in itself, however, that represents a eugenic threat, but rather the potential for social uses to be made of it. Although consensus is lacking on the definition of eugenics, the general agreement is that the term refers to practices aimed at improving the hereditary traits of the human species through deliberate intervention. Viewed from this angle, preimplantation genetic diagnosis is too marginal a practice to be considered eugenic.

The World Health Organization defines eugenics as "[a] coercive policy intended to further a reproductive goal, against the rights, freedoms, and choices of the individual," thereby emphasizing the importance of protecting individuals from a collective force. To avoid rhetorical distortion and to better understand the ethical issues associated with practices that link genetics and reproduction, it is wiser not to place all such practices under the heading of eugenics without nuance. For example, offering the selection of embryos for the avoidance of rare disorders may be considered by some to be discriminatory or immoral. But as long as this practice is not imposed, it is only potentially eugenic. This argument is all the more pertinent given that the technical limitations inherent in preimplantation genetic diagnosis do not even allow for its use in the service of any eugenic policy. ${ }^{7}$ Moreover, genetic diagnosis of embryos requires prior in vitro fertilization and all the procedure entails; ${ }^{8}$ it is expensive and it does not allow for a large number of children per family. ${ }^{9}$

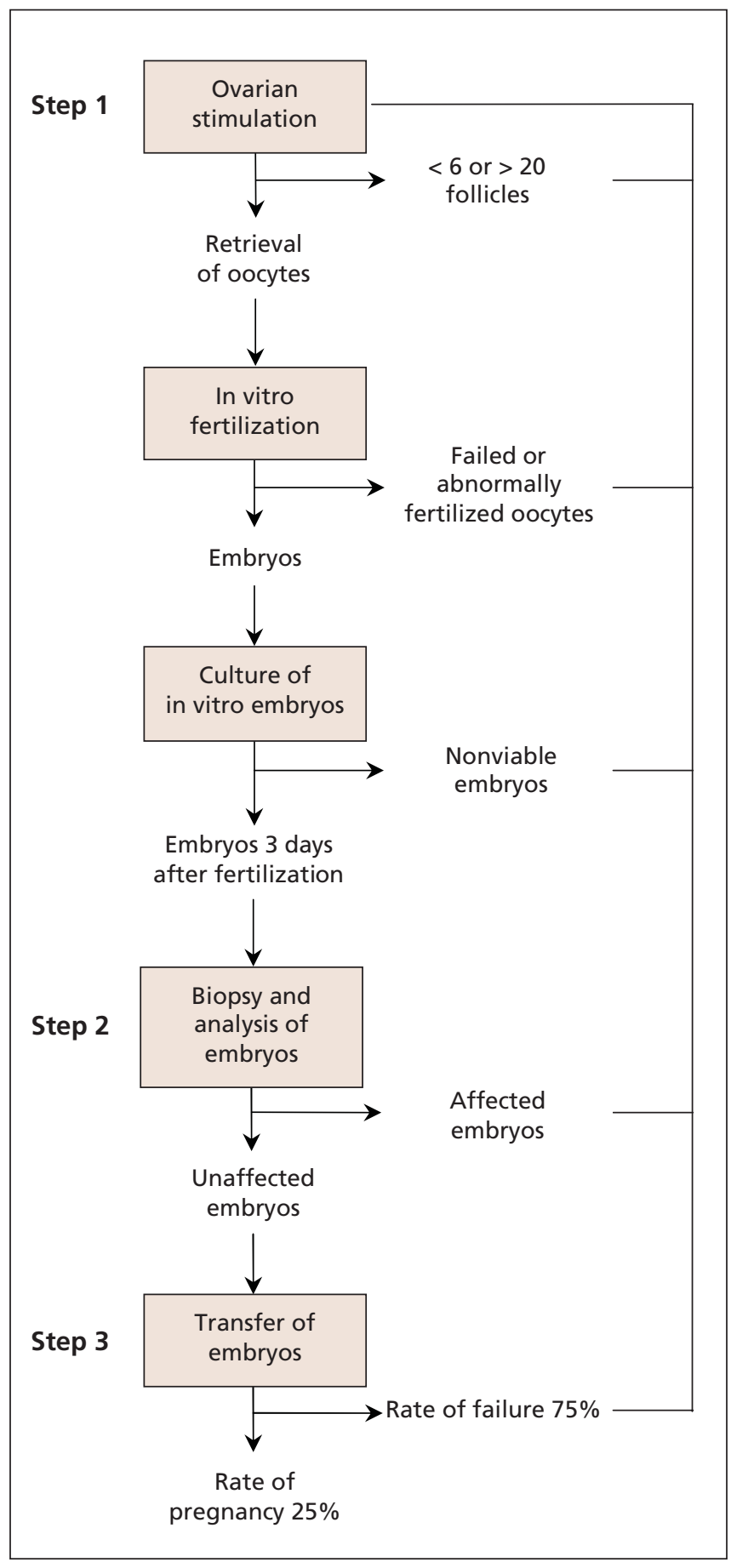

Figure 2: Preimplantation genetic diagnosis is a 3-step, 8-day technique used to identify single-gene defects or chromosomal anomalies in embryos before in vitro fertilization. Each step presents significant risks of failure that can lead to postponement. 
In short, this technique is too complex and humanly too exacting to be seriously considered "eugenic." A society that would wish to rid itself of all embryos that did not satisfy certain criteria would resort to prenatal diagnosis, not genetic diagnosis of embryos, since diagnosing fetuses is more feasible, less expensive and more cost effective. Finally, most countries have placed legal and ethical limitations on preimplantation genetic diagnosis (Appendix 4, available at www.cmaj.ca/cgi/content/full/cmaj.080658/DC1). ${ }^{10}$ For example, some countries, including Austria, Germany and Switzerland, legally prohibit the technique. Others, including the United Kingdom, France and the Netherlands, permit it with certain exceptions. In Canada, preimplantation genetic diagnosis is permissible under the legislative framework of the law on assisted human reproduction. The United States has no legal regulations but allows the technique to be regulated by professional standards.

\section{"The perfect child"}

The notion of "the perfect child," which is associated with that of the designer baby, is linked to a widespread belief that unbridled parental autonomy ${ }^{11}$ will lead to reproductive programming. From this perspective, genetic diagnosis of embryos is seen as interfering with the natural order (presumed to be static) and as limiting the "open future" of every child. It is also seen as an affront to those already living with disabilities $^{12}$ and as one more incentive for discrimination. ${ }^{13}$ Some opponents of the procedure further claim that current low birth rates can only contribute to a trend toward seeking the perfect child.

In reality, the notion of the "à la carte creation" of the perfect child through genetic diagnosis of embryos underestimates the complexity of the human condition. Every individual is the result of genetic heredity but also of the influence of coevolution with other species, coadaptation with the environment, and gene-gene interactions. The phrase "the perfect child" also prejudges the motives of parents seeking genetic diagnosis of embryos as being necessarily eugenic. Studies on the subject show that those who resort to this technique do so to avert the birth of children with severe, often fatal diseases with which they themselves already have experience. ${ }^{14}$ So far, no data confirm that parents want a perfect child ${ }^{15}$ as distinct from a child that is not afflicted with a serious disease, implying a more relative reasoning.

The notion of the perfect child is somewhat more consistent with situations of parental desire for sex selection and with the deliberate implantation of embryos that have genetic conditions such as deafness or shortness of stature. However, the number of applications for preimplantation genetic diagnosis with these ends in view remains so small as to render them marginal. Therefore, such uses can easily be prohibited. The International Bioethics Committee of UNESCO considers the deliberate implantation of embryos that have genetic conditions unethical because it does not take into account the many lifelong and irreversible disadvantages that will burden the future person. ${ }^{16}$

Conceptual distortions prevent effective discussion about evidence both for and against a given technique. They affect our ability to fairly discuss innovations and the promise these may hold and they curtail discussions about potential perils. More importantly, the warping of public perceptions seriously limits the potential for documenting all of the benefits and harms of the real-life choice to use preimplantation genetic diagnosis. This choice is often based on community or familial experiences of living with disability, in contrast to alarmist speculation on how such choices are made. Simplistic conclusions based on fictitious scenarios make for bad policy.

\section{Fiction versus reality}

When preimplantation genetic diagnosis is viewed as a eugenic technique and a way to produce the perfect child, the technical limitations of the procedure and the real-life experiences of patients are ignored. Moreover, this view fails to take into account certain socioethical problems that are more current than the threat of eugenics or the production of perfect children. The provision of genetic diagnostic testing at the embryonic stage is already subject to controversial individual, religious, medical, economic, cultural and ideological interests.

For example, the sex selection of embryos for "social" reasons and the selection of embryos with a specific disease or disorder (in the expectation that the affected child will integrate better into the family) are much more closely associated with cultural, ideological and individual imperatives than medical ones. The prohibition against providing certain diagnostic services to same-sex parents and single parents constitutes discrimination against people who may carry or are affected by a serious disease. Religious prohibition of genetic prenatal diagnostic testing and lack of access due to economic obstacles also generate ethical issues and few studies have been done on their impact.

There are a number of other important considerations. For example, should we permit the use of genetic diagnosis based on cosmetic considerations? ${ }^{17}$ Should we permit screening of embryos for predisposing genes to fatal but potentially treatable diseases such as cancer ${ }^{18}$ and multifactorial or cardiovascular diseases? ${ }^{8}$ What about equity and access to this expensive novel technology? Finally, how do we deal with "reproductive tourism" (travelling to another country to obtain assisted-reproduction services that are not available or are prohibited in one's own country) created as a result of stringent regulations in our own country? Note too that lack of follow-up of children born following the use of preimplantation genetic diagnosis is also an issue. ${ }^{8}$

It is our view that these socioethical problems merit a degree of attention and media coverage equal to that given to the issues of eugenics and the making of the perfect child.

\section{Reality as fiction}

Distortions curtail research by shaping public perceptions. Not only do they influence politicians and lawmakers to adopt or change laws and regulations, but they risk seriously inhibiting freedom of research and the ability to initiate studies and recruit patients. ${ }^{19}$ Experts must lead by example, rely on evidence, and avoid the use of loaded terms. Most importantly, there is a need to educate decision-makers and the public by 
encouraging them to listen to and learn from the stories of the families that seek recourse to these techniques. We will then be able to conduct studies that will better describe all of the risks and benefits of these new techniques.

A better understanding of the clinical conditions and technical realities of preimplantation genetic diagnosis, together with greater openness to learning about the experiences of patients and their families, would do more for the establishment of realistic ethical and legal frameworks than inflammatory language. To take this approach requires ongoing research into the real-life situations that call for the painful decision-making that is associated with choosing to use genetic diagnosis of embryos. Such an evidence-based approach would be more equitable and more concerned with analyzing the real risks and benefits for the hoped-for child, the parents and society. ${ }^{20} \mathrm{We}$ would also gain by better understanding the medical, social and ethical repercussions of the various regulatory systems adopted in other countries. In societies where knowledge and power are inextricably linked, we have a responsibility to develop our own knowledge about the medical, ethical and social repercussions of genetic diagnosis of embryos.

Inflammatory language can awaken us to the existence of certain issues, which is good; but what are needed are reflection and empirical research, not reactions based on inflammatory language, whether for or against a given development. It is important to beware of eugenics and discrimination. But this vigilance is not sufficient by itself to ensure that the regulatory measures we devise will be respectful of the individuals who submit to them. If we really have an appetite for speculative fiction, we should rise to the occasion and ask what impact our current ethical positions on preimplantation genetic diagnosis will realistically have on the future.

Key terms are defined in Appendix 1, available at www.cmaj.ca /cgi/content/full/cmaj.080658/DC1.

This article has been peer reviewed.

Competing interests: None declared.

Contributors: All of the authors contributed to the development of the concepts in the manuscript, and all drafted, revised and approved the final version submitted for publication.

Acknowledgements: We wish to thank Professors Arnold Munnich and Régen Drouin for their useful comments. Special thanks to Céline Moutou and Philippe Gosset for Figure 1.
Funding: This work was supported by the International Institute of Research in Ethics and Biomedicine, the Fonds de recherche en santé du Québec and the Stem Cell Network of Canada.

\section{REFERENCES}

1. Klipstein S. Preimplantation genetic diagnosis: technological promise and ethical perils. Fertil Steril 2005;83:1347-53.

2. Knoppers BM, Bordet S, Isasi RM. Preimplantation genetic diagnosis: an overview of socio-ethical and legal considerations. Annu Rev Genomics Hum Genet 2006; 7:201-21.

3. Feyereisen E, Frydman N. Preimplantation genetic diagnosis. Rev Prat 2006; 56:513-9.

4. Bouffard C, Godin JK. Pratique éthique de la confidentialité dans le cadre du diagnostic préimplantatoire français. In: Duguet AM, Filippi I, editors. Dossier médical et données médicales de santé. Protection de la confidentialité, conditions d'accès, échanges pour les soins et la recherche. Bordeau (France): les Études Hospitalières; 2006. p. 219-38.

5. Hudson KL. Preimplantation genetic diagnosis: public policy and public attitudes Fertil Steril 2006;85:1638-45.

6. World Health Organization (WHO). Review of ethical issues in medical genetics: Geneva: World Health Organization; 2003. Available: www.who.int/genomics /publications/en/ethical_issuesin_medgenetics\%20report.pdf (accessed 2009 May 7).

7. Baum M. Pre-implantation genetic diagnosis (PGD): the spectre of eugenics or a "no brainer." Int J Surg 2006;4:144-5.

8. Soini S. Ibaretta D, Anastasiadou V, et al. The interface between assisted reproductive technologies and genetics: Technical, social, ethical and legal issues. Eur J Hum Genet 2006;14:588-645.

9. Mastenbroek S, Twisk M, van Echten-Arends J, et al. In vitro fertilization with preimplantation genetic screening. N Engl J Med 2007;357:9-17.

10. Knoppers BM, Isasi M. Opinion: regulatory approaches to reproductive genetic testing. Hum Reprod 2004;19:2695-701.

11. Parker M. The best possible child. J Med Ethics 2007;33:279-83.

12. Shakespeare T. Disability rights and wrongs. Abingdon (UK): Routledge; 2006. p. 240

13. Krahn T. Where are we going with preimplantation genetic diagnosis? CMAJ 2007; 176:1445-6.

14. Roberts C, Franklin S. Experiencing new forms of genetic choice: finding from an ethnographic study of preimplantation genetic diagnosis. Hum Fertil(Camb) 2004; 7:285-93.

15. Kalfoglou AL. PGD patients' and providers' attitudes to the use and regulation of preimplantation genetic diagnosis. Reprod Biomed Online 2005;11:486. Available at: www.rbmonline.com/Article/1818 (accessed 2009 May 7).

16. International Bioethics Committee (IBC) of the United Nations Educational, Scientific and Cultural Organization (UNESCO), Report of the IBC on Pre-implantation Genetic Diagnosis and Germ-line Intervention. Paris: UNESCO; 2003. Available at: http://unesdoc.unesco.org/images/0013/001302/130248e.pdf (accessed 2008 Sept. 21).

17. Bromage DI. Prenatal diagnosis and selective abortion: a result of the cultural turn? Med Humanit 2006;32:38-42.

18. Harris M, Winship I, Spriggs M. Controversies and ethical issues in cancer-genetics clinics. Lancet Oncol 2005;6:301-10.

19. Wilkinson S. "Eugenics talk" and the language of bioethics. J Med Ethics 2008, 34:467-71

20. Klitzman P, Appelbaum PS, Chung W, et al. Anticipating issues related to increasing preimplantation genetic diagnosis use: a research agenda. Reprod Biomed Online 2008;17(Suppl 1):33-42.

Correspondence to: Dr. Chantal Bouffard, Department of

Pediatrics (Genetics), Faculty of Medicine and Health Sciences, Université de Sherbrooke, 3001, 12e Avenue N, Sherbrooke QC

J1H 5N4; fax 819-564-5217; chantal.bouffard@usherbrooke.ca 